\title{
META-ANALYSIS: THE EFFECT OF SMARTPHONE USE ON THE INCIDENCE OF LOW BACK PAIN IN ADOLESCENTS
}

\author{
Yenni Kurniawati, Bhisma Murti
}

\author{
Masters Program in Public Health, Universitas Sebelas Maret
}

\begin{abstract}
Background: The smartphone is one of the most popular technological devices among many ages worldwide. Innovations in smartphone models, including surfing the internet, social media apps, gaming apps, portable media players, compact digital cameras, and high-resolution touchscreens, have been a factor in the frequent use of and "addiction" to smartphones. Addiction to smartphones can cause serious problems, especially for students, such as incorrect posture, musculoskeletal disorders, and low back pain. This study aimed to examine the effect of smartphone use on the incidence of low back pain in adolescents.
\end{abstract}

Subjects and Method: This was a systematic review and meta-analysis. A systematic review was conducted using the Google Scholar, PubMed, and ScienceDirect databases and the following search criteria: "Smartphone" OR "Mobile Phone" OR "Handphone" AND "Low Back Pain" OR AND "Adolescent" OR "Teenage” AND "logistic regression". The articles were filtered using PICO model, including: (1) Population= adolescents, (2) Intervention $=$ smartphone use $\geq 6$ hours $/$ day, (3) Comparison $=$ smartphone use $<6$ hours/ day, and (4) Outcome= low back pain. The inclusion criteria were full text, case control study, published from 2014 to 2021, and reported adjusted Odds Ratio (aOR). The systematic review was carried out according to the PRISMA guidelines. Quantitative data were assessed by meta-analysis using RevMan 5.3.

Results: A meta-analysis involved 7 primary studies from Brazil, China, Ethiopia, Saudi Arabia, Switzerland, and Thailand. The result of this study was smartphone use $\geq 6$ hours/ day increased the risk of low back pain in adolescents ( $\mathrm{aOR}=3.80$; $95 \% \mathrm{CI}=$ 2.56 to $5.65 ; \mathrm{p}<0.001$ ).

Conclusion: Smartphone use $\geq 6$ hours/ day increases the risk of low back pain in adolescents.

Keywords: smartphone, mobile phone, low back pain, adolescents

\section{Correspondence:}

Yenni Kurniawati. Masters Program in Public Health, Universitas Sebelas Maret. Jl. Ir. Sutami 36A, Surakarta 57126, Central Java. Email: Yenni.kurniawati27@student.uns.ac.id. Mobile: 082226247289 . 